\title{
Modos de construcción de la memoria en la primera novela chilena experimental antidictadura: El paso de los gansos (1975) de Fernando Alegría.*
}

\section{Ways of Constructing Memory in the First Experimental Antidictatorship Chilean Novel: El paso del ganso (1975) by Fernando Alegría.}

\section{Resumen}

Este artículo se dedica a evidenciar los modos de construcción de la memoria y la crisis de representación en la novela El paso de los gansos (1975) de Fernando Alegría (1918-2005). El volumen, otorga un lugar preferencial a Cristian Montealegre ${ }^{1}$, fotógrafo y víctima de la represión, cuyas fotografías operan como testimonio de su experiencia en el contexto de los dos primeros meses de la dictadura. De esta forma, una de las dos primeras novelas chilenas antidictadura expone el golpe y las crisis que este hecho desata por medio de la intensificación de la relación entre palabra e imagen.

Palabras claves Memoria, novela chilena, novela experimental, Fernando Alegría, fotografía, Golpe Militar Chile.

* Este artículo se deriva de mi proyecto FONDECYT $\mathrm{N}^{\circ}$ 1150288, Años 2015-2016-2017: "Novela chilena de fin de siglo XX e inicio del siglo XXI: memoria y pervivencia del imaginario de la dictadura militar".

${ }^{1}$ Este personaje se basa en: "Cristian Mortecinos Slaughter. Fotógrafo 'free lance' y cineasta, chileno-norteamericano. El 17 de octubre de 1975, en Santiago, fue secuestrado de su departamento y fusilado esa misma noche en el túnel Lo Prado". $<\mathrm{http}: / /$ www.puroperiodismo.cl/?p=23287> [Revisado 18, abril 2016]. 


\begin{abstract}
This article presents evidence of both the ways in which memory is constructed and the crisis of representation in the novel El paso de los gansos (1975) by Fernando Alegría (19182005). This volume gives prominence to Cristian Montealegre, a photographer and victim of the repression, whose photographies are testimony of his experience within the context of the first two months of the dictatorship. On this way, one of the two first Chilean antidictatorship novels exposes the coup d'etat and the crisis of this fact unleashes through the intensification of the relationship between word and image.
\end{abstract}

Keywords Memory, Chilean novel, experimental novel, Fernando Alegría, photography, Coup d'état Chile.

La nueva novela (1977) de Juan Luis Martínez, El rincón de los niños (1980) de Cristián Huneeus, Lumpérica (1983) de Diamela Eltit, publicados en Chile durante los primeros diez años de la dictadura, conforman un corpus de obras catalogadas como experimentales, ya que se trata de escrituras que ponen en escena tanto la crisis del género novela, como del propio lenguaje y los modos de representación. Por lo mismo, hablamos de obras postépicas, fragmentarias, que acusan los efectos de la violencia en la letra, la disposición, la configuración de la trama, proliferante en imágenes, puntos de vista multifocales, superposición de planos. Se trata, en definitiva, de lo que podemos denominar escrituras de la devastación representacional. No estamos aquí frente a cualquier tipo de experimentalismo, sino ante uno muy particular, producido al interior de la represión postgolpe de Estado y donde la función metaliteraria está en la superficie de los textos, es decir, la reflexión en torno a los modos de decir se encuentra en medio de la catástrofe. Desde mi perspectiva, resulta necesario abordar este conjunto en tanto literatura postutópica, sin perspectiva de futuro, donde es posible advertir la constatación de la derrota y, por lo mismo, la negación total de la instalación de una épica de reemplazo. Es en este corpus, donde inscribo El paso de los gansos (1975) de Fernando Alegría (1918-2005) novela que abordaré a partir de dos preguntas: ¿sin épica ni utopía, es posible la 
resistencia frente al sistema de poder? y, ¿en cuáles de los usos de la memoria es posible inscribir a esta narrativa de la devastación?

Fernando Alegría, nacido en 1918, fue un destacado novelista, cuentista, biógrafo, ensayista y crítico literario, vivió desde 1940, más de la mitad de su vida, en Estados Unidos, desempeñándose como académico e investigador literario. Perteneciente a la generación del '38, Alegría tiene una amplia producción novelesca y ensayística donde destaca su interés épico por personajes chilenos como Recabarren (1938), Lautaro, joven libertador de América (1943), Allende, mi vecino presidente (1990). Durante el gobierno de la Unidad Popular fue Agregado Cultural de Chile en Washington y el 11 de septiembre se encontraba en Santiago de Chile, preparando una biografía de Salvador Allende, con quien mantenía una estrecha amistad. (Guerra 29-30)

El paso de los gansos coincide con la publicación de Soñé que la nieve ardía (1975), primera novela de Antonio Skármeta. Ambas obras, publicadas en el exilio, transitan por el tiempo previo y posterior al Golpe Militar. Es necesario remarcar que tanto la obra de Skármeta como la de Alegría, desde flancos opuestos, se constituyen como las dos primeras ficciones chilenas en torno al Golpe Militar y sus efectos inmediatos. Sin embargo, la novela de Skármeta se inscribe dentro de lo que podemos llamar literatura de resistencia utópica, aquellas producciones centradas en la catástrofe chilena, donde se afirma la utopía, un futuro de recomposición del orden. Alegría, por su parte, se instala en otro territorio, bastante más difícil de definir y clasificar, aunque sin duda, postutópico.

En el ejemplar 19 de Revista Araucaria de Chile ${ }^{2}$, correspondiente al año 1982, Fernando Alegría publica el artículo "La literatura chilena en el contexto latinoamericano”. Al inicio de este texto señala: “¿Es posible concebir una literatura sin ideología? dudoso y, acaso, más dudoso sea imaginar a un creador

${ }^{2}$ Revista que se publica en el exilio, específicamente en Estados Unidos, entre 1978 y 1989, alcanzando la cifra de 37 ejemplares. Fue dirigida por Volodia Teitelboim y tuvo como Secretario de Redacción a Carlos Orellana. 
CATEDRAL Tomada: Revista de crítica literaria latinoamericana / Journal of Latin American Literary Criticism Modos de construcción de la memoria en la primera novela chilena experimental antidictadura:

El paso de los gansos (1975) de Fernando Alegría.

literario que escriba al azar, como decir, siguiendo la dirección de los vientos" (Alegría, La literatura chilena 113) para luego, hacia el final, agregar:

El mensaje es claro: No basta escribir bien, es necesario que la buena literatura actúe como un arma de liberación ${ }^{3}$. El viejo debate sobre la legitimación de la política en la obra de arte ha perdido toda relevancia en la era de asaltos a la cultura, de violación de los derechos humanos, de armamentismo suicida y abusos imperialistas en que vivimos. Todo lo que hagamos o no hagamos en este trance será político y nos comprometerá en nuestra lucha, en nuestro sacrificio o en nuestra renuncia. (Alegria, La literatura chilena 119)

Lo anterior implica no solo afirmar el compromiso literario, sino atribuirle a la literatura la función liberadora. Es así como una obra literaria tendrá utópicamente, la misión de compensar pero también, en tanto arma, confrontar al enemigo. Como buen representante de la Generación del 38, para Alegría la literatura posee la función de testimoniar la historia, por lo mismo su novela pretende dejar un registro de los hechos desde el lugar de los vencidos, asumiendo una perspectiva contra histórica, divergente con la versión hegemónica.

El problema es que en El paso de los gansos las declaraciones antes señaladas por Alegría, respecto a la literatura, parecen haber quedado anuladas o, por lo menos, aplastadas bajo el peso de la derrota. La novela dedica cuatro de sus cinco capítulos a la historia personal y política de Allende y del Golpe de Estado, al modo de relatos descentrados, emitidos por voces narrativas diseminadas, donde proliferan múltiples puntos de vista sobre el ex presidente Salvador Allende, las motivaciones que desataron su muerte y el Golpe Militar. Sin embargo, el último capítulo de la novela, sí posee un centro. Se trata de la voz narrativa de Cristian Montealegre, un joven chileno desarraigado, que vuelve al

\footnotetext{
${ }^{3}$ El destacado es mío.
} 
país dos meses antes del Golpe, experimentando una crisis existencial que coagula en el compromiso político.

El paso de los gansos es una novela que desarticula, de tal modo, los centros, diversifica las voces, enfatiza los quiebres temporales, convocando formatos como la crónica, el diario de vida, la entrevista, el testimonio, la memoria y los protocolos novelescos. Se trata, en definitiva, de la confluencia de registros ficcionales y referenciales que, en su conjunto, darían lugar a una novela-dispositivo fragmentaria. Tanto la historia del país, como la de los sujetos nominados e innominados que circulan por sus páginas, son abordados a partir de tramos, nunca de manera integral o totalizante. De igual modo, ocurre con la historia política del país, conformada al modo de una red de versiones-vectoresdiscursos, que confluyen o se distancian en sus puntos de vista. Esto implica la imposibilidad de asumir un relato de origen o causalista; pérdida, por tanto, del estatuto de unicidad y autenticidad. En su reemplazo, nos enfrentamos a la fractura de la verdad, donde la polifonía testimonia la imposibilidad de interpretar lo real de modo unilateral.

Esto, resulta particularmente interesante sobre todo en el contexto de los relatos que la resistencia a la dictadura requería. Alegría no arma, no reconstruye una verdad, más bien la desmonta. Aunque ubicado sin ambigüedad alguna en la oposición a Augusto Pinochet, claramente el autor no está produciendo una herramienta antidictadura literalmente útil, al modo de lo que fueron las canciones de la resistencia, los relatos testimoniales de las víctimas, los discursos de recomposición del orden, los llamados a la sublevación.

En términos globales, podemos sostener que la novela se estructura en base a dos regímenes de configuración de lo real, el primero convoca a la memoria colectiva, y el segundo a la memoria individual. Sin embargo, con el régimen de la memoria colectiva ocurre un problema, a saber: no puede ser utilizado, no sirve para la construcción de una épica, ya que configura una memoria fragmentada, desarticulada, en ruinas. La propia figura de Allende, de quien se destaca su extraordinario apego y consecuencia con sus ideales, es 
sometida a críticas feroces en su apego burgués a las reglas, es decir, se revela lo que podría ser el germen de su fracaso como revolucionario. Por su parte, el régimen de memoria individual, en torno a Cristian, si bien posee un grado de articulación mayor al focalizarse en la materialidad de los hechos experimentados por el personaje, enfatizando la presencia de sexo y misticismo materializado en una visión panteísta, expone una diseminación del punto de vista heroico en medio de un contexto multifocal, desbordante de cadáveres, fusilamientos, ametrallamientos, desapariciones.

Es precisamente en medio de la memoria individual en crisis de Cristian, donde surge el antiutopismo. Más aun, es posible constatar la presencia de una visión casi profética respecto al país:

Ayer se quebró Chile. Lo que desataron los militares nunca lo podrán remediar. No supieron hacer las cosas. Ambos lados están ahora en una lucha fratricida que no terminará en una generación. No habrá cientos de muertos como hoy y ayer, pero desangrarán al país poco a poco $[\ldots]$ Chile es ahora un país sin salida. (Alegría, El paso 113)

Chile es un país sin ruinas ni reliquias, el futuro pide vidrio y acero y altura. (200)

¿Qué será de Chile? Quiero decir en algunos años más, bastantes años. Los que hoy celebran la carnicería, los que salieron a matar con sus revólveres y pistolas particulares, las gruesas madonas que besaron a sus soldados, se cansarán y perderán el sentido de todo su entusiasmo. También morirán. Habrán perdido parientes y amigos. La sonrisa será de hueso y los sobrevivientes entre ellos comenzarán a protestar y a rebelarse, perderán el miedo, pedirán libertad, buscarán a los 


\section{tribunos otra vez y querrán elecciones. Se prepararán para los nuevos negocios ${ }^{4}$. (145)}

El personaje afirma el quiebre del país, acusando por tanto el Golpe Militar en su función material y simbólica, la imposibilidad de su reconfiguración y una visión proyectiva decadentista, donde se consolidará la tachadura de la memoria, y la emergencia de una modernidad dominada por leyes mercantiles. Destaca en las citas anteriores, la afirmación: "No supieron hacer las cosas" (Alegría, El paso 113), lo cual incluye dos polos, a saber: el frente golpista versus los miembros de la Unidad Popular. Esta perspectiva incluyente en términos de responsabilidades, sitúa a la voz narrativa en una posición exotópica, orientada a equilibrar las razones que motivaron la debacle. En términos de futuro, Cristian sostiene una visión distópica, en tanto la reconfiguración del orden será posible solo bajo las coordenadas de un orden político centrado en lo económico.

Cristian Montealegre es cristiano, cercano a la teología de la liberación, vive en crisis permanente con su familia y su clase, pero esto no impide que asuma que su lucha se remite a testimoniar la realidad a través de las imágenes. Concibe como un deber recorrer la ciudad retratando la masacre con su cámara fotográfica de aficionado, en algunas ocasiones junto a su hermano Marcelo, fotógrafo profesional. Cristian así señala: "Yo pasaba a buscar a Marcelo en la BMW-500 y salíamos juntos a tomar fotos. La ciudad era, en el sol esplendoroso de la primavera, un campo abierto de hombres armados y gente aterrada" (Alegría 181). El narrador identifica dos niveles espaciales. Por un lado la altura, el marco que impone la naturaleza bullente, ajena al mal imperante. El segundo espacio reconocido, es el terrestre, conformado por hombres armados versus gente aterrada. El sujeto se ubica en el territorio de la confrontación terrenal, material, donde el horror es capaz de intervenir incluso en su arte:

\footnotetext{
${ }^{4}$ El destacado es mío.
} 
De repente, cae de espaldas un joven padre en la Plaza Constitución, se queda inmóvil con un balazo en la frente, crece alrededor de su cabeza una pequeña poza de sangre, sin brillo, demasiado espesa para ser épica, y los niños que llevaba de la mano se hincan a su lado y tratan de ayudarle a levantarse [...] La imagen de esta muerte está en la lente de mi cámara, pero no empieza a decirme nada hasta que esa imagen y mi ojo aparecen juntos por primera vez, cuando empiezo a desarrollarla y en la cámara oscura me voy revelando también, las pestañas mojadas con sangre, el temblor de mis manos; los niños y yo estamos esperando que la imagen se anime y empiece otra vez a andar. Y, de pronto, somos dos los muertos, él y yo, entonces el estupor se hace angustia y, poco a poco, vergüenza. (177)

Ubicado en el centro cívico de la ciudad capital, frente a la Casa de Moneda bombardeada, Cristian es testigo de un crimen, la víctima es identificada como un "padre", un sujeto anónimo, limitado a su función familiar, desprovisto de armas, rodeado por sus pequeños hijos. Es necesario destacar el siguiente enunciado de la cita anterior: "una pequeña poza de sangre, sin brillo, demasiado espesa para ser épica", donde Cristian advierte la opacidad de aquella muerte, la cual quedará en el anonimato, desasida de épica y, por tanto, de heroísmo. Es interesante consignar que la imagen de este crimen se encuentra en la cámara fotográfica de Cristian, convertida en un testimonio que trasciende la muerte, adquiriendo vida o manteniéndose con vida, a través de dos acciones: destila sangre y humedece el ojo de Cristian que la visiona.

La vinculación entre Cristian y la realidad fracturada, constituida por planos, se hace cada vez más intensa, transitando férreamente por un proceso de compromiso con la historia, así agrega: "se nos exigió, de pronto, considerar la palabra conciencia. Y reaccioné con pena, acusé el golpe” (177). El sujeto recibe el Golpe, a nivel individual, biográfico, asumiendo una responsabilidad inexcusable. Se trata, de tal manera, de la adopción de la función testimonial, 
asume entonces la misión de elaborar un registro visual, mediante imágenes, de la catástrofe que se impone en la realidad, así dice:

Traté de fotografiar y en el lente vi una imagen quebrada: una cara joven en un instante entera y segundos después deshaciéndose como si fuera de goma y la borraran y lo que fue cara se abrió grotescamente, lentamente, perdió sus orillas, se hizo labios y desapareció o se confundió con el cielo rojo, lleno de humo. El suelo también se abría. Los tanques disparaban sus cañones. Y entonces vi mi propio ojo desorbitado, sin pestañas, goteando sangre, y nada más. (166-167)

La cámara fotográfica se convierte, entonces, en el dispositivo que permite al personaje experimentar, a nivel fragmentario, el golpe que recibe la realidad material, que incide en la destrucción de las formas y luego en su desaparición. Este hecho, se encuentra en sintonía con la acción ejecutada por las fuerzas militares que detenían y desaparecían los cuerpos de todo aquel sujeto que se manifestara en oposición al terrorismo instaurado. El protagonista, transita así por un territorio golpeado, por sujetos golpeados, expuestos a la destrucción, proceso que incluye su propia materialidad. El cuerpo de Cristian es herido, mediante la metonimia, el ojo acusa el golpe, convirtiéndolo en una víctima más de la violencia física, material que implica, además, el cercenamiento de su misión, ya que el personaje privilegia la imagen al discurso lo cual queda expreso en la siguiente cita:

Eran ruinas que debía recoger en imágenes antes que se convirtieran en ideas [...] Fuimos con Marcelo a la Morgue y tomamos algunas fotos, escenas violentas en su escalofriante brevedad [...] vi a unas mujeres y me acerqué a fotografiarlas y la imagen resultó como un bajo relieve de sombras y ojos, la noche contra el día, figuras saliéndose de la pared, rascando, enlutadas, llenas de polvo. (189) 
La realidad se ha fracturado en lo terrestre y en lo corpóreo, en la forma; sin embargo el personaje advierte que aquello que reconoce como ruina, puede ser recogido "en imágenes" fotográficas. Se trata, de tal modo, de la conjunción de una práctica artística y la conformación de una fuente documental capaz de trascender la condición de idea o verdad histórica que construirá el vencedor. Cristian elaborará lo que será su pasado, su memoria, la cual desde la perspectiva de Bellido: “[...] es un conjunto de recuerdos no necesariamente ordenados que se materializan en forma de representación, rememorada por sus protagonistas o por el colectivo al que le concierne" (106). La imagen no resulta desligada de su estatuto artístico, sino que suma la función documental para constatar y verificar la existencia de la catástrofe, prefigurando con ello, no solo una época donde la imagen llegará a ocupar el sitio de la escritura sino que al mismo tiempo situando a la imagen como referencial privilegiado de realidad, para contrarrestar la conformación de la realidad mediante ideas. Respecto al carácter de verosimilitud que puede tener el relato del testigo de una catástrofe, Carlos Pabón recoge la reflexión de Primo Levi:

[un] problema importante que ha obstaculizado el alcance de los testimonios ha sido la falibilidad de la memoria. Levi se refiere al problema de la "escasa confiabilidad" de la memoria así: "La memoria humana es un instrumento maravilloso, pero falaz [...] Los recuerdos que en nosotros yacen no están grabados sobre piedra; no sólo tienden a borrarse con los años sino que, con frecuencia, se modifican o incluso aumentan literalmente, incorporando facetas extrañas". (15)

Precisamente por este carácter falible que se le atribuye a la memoria, es que el protagonista privilegia la imagen de cuerpos víctimas de la violencia como referencial verosímil, incuestionable ante la duda respecto a la palabra la cual, al igual que la historia, deberá someterse en un futuro a un juicio crítico (Pabón 18). 
La confianza que el personaje manifiesta respecto a la memoria individual se vuelve de tal manera fundamental. Se trata, a fin de cuentas, de una memoria articulada por el Golpe Militar. Es este hecho el detonante de todo aquello que acontece y emerge en esta narración, donde las figuras de Salvador Allende y Cristian Montealegre, operan como símbolos privilegiados respecto a la emergencia del héroe y la utopía. Allende y Montealegre, en cada una de sus apariciones y menciones, dan cuenta de un estado de conmoción personal y social. Se trata de dos sujetos que representan a la clase media alta chilena donde destacan rasgos como la contención, el temor a la radicalidad, que deriva en un actuar mesurado, sostenido en una ideología burguesa en crisis permanente, donde se rechaza el determinismo de clase. Aun cuando Allende se identifique como marxista y Montealegre cristiano, ambos se sostienen en un ideario valórico humanista que en última instancia los lleva a convertirse en mártires pero también en individuos dogmáticos, ingenuos en su actuar y en las consecuencias de sus decisiones.

Esta conformación de los personajes, que cumplen un rol protagónico en la narración, implica que el heroísmo adquiera, a lo menos, dos dimensiones. Mientras la figura de Allende representa el mito del pasado, en el presente del relato, en medio de la debacle, Cristian, ya no accede a la condición de héroe, sin embargo destaca en el personaje, su deseo de futuro y, por tanto, deseo de utopía, resignificada esta última, por la función testimonial que asume. Es, precisamente, la conjunción de futuro-utopía-testimonio el indicador de una fuerza emergente que podemos denominar resistencia ante el otro o macrofigura de la violencia. Sin embargo, en el presente, el otro también es el sujeto inscrito en las imágenes de aniquilación y, en el futuro, el destinatario del testimonio.

Quisiera detenerme un momento en la figura de Cristian Montealegre, joven fotógrafo, hermano menor de Marcelo, también fotógrafo. La figura de Cristian se basa en Cristian Montecino (1946), joven fotógrafo, al igual que su hermano Marcelo, y cineasta, asesinado por la dictadura. Cristian vivía en Estados Unidos y durante el Golpe se encuentra en Chile, desde julio de 1973, 
viviendo, como señala la novela, en las Torres San Borja. Sin militancia alguna, tras ser denunciado por una vecina que operaba como agente de los servicios represivos, el 16 de octubre de 1975, su cadáver fue arrojado “en el kilómetro 12 de la carretera Santiago/Valparaíso, sector del Túnel” (Opaso, s/p). Montecino mantuvo un Diario de vida entre agosto y octubre del mismo año, cuyas últimas escrituras datan hasta seis días antes de su asesinato (Opaso s/p). Alegría recoge estos hechos y los utiliza como material de su ficción, potenciando la figura del joven, desplazándose en moto, fotografiando Santiago el 11 de septiembre y días posteriores. De igual forma, se profundiza en su relación con Luz María, una joven rebelde, perturbada, inserta en una búsqueda existencial tan profunda como la del propio Cristian. Una vez ocurrido el Golpe, Luz María se hace parte de la resistencia e involucra a Cristian en labores de protección a militantes en la clandestinidad. Sin embargo no es la labor de ayudista de Cristian la que lo lleva a la muerte, sino que la delación vecinal. Este hecho es expuesto en la novela como una forma de mostrar el trasfondo cívico-militar de la represión, que no solo vino de arriba hacia abajo, sino que tuvo una aterrorizante forma transversal. En el capítulo "El evangelio según Cristian”, uno de los más extensos del volumen, la narración configura la relación del personaje con un sacerdote que expone un discurso de conciliación y la reflexión de Cristian en torno a su visión cristiana ligada a la paz y en equilibrio entre hombre y naturaleza. Sin embargo Cristian también es expuesto en su condición degradada; es un hombre inseguro, indiferente con sus hijos, violento con su pareja. Alegría insiste en mostrar el carácter bidimensional a sus protagonistas, lo cual no solo incide en la desacralización de su condición heroica, sino en la confirmación de la imposibilidad de heroificar tras la catástrofe experimentada en el país.

Esta narración, de tal forma, se configura como un espacio de negatividad profundo. Sin épica, sin heroicidad, sin utopía, solo queda en pie la catástrofe, el deseo de testimoniar del sujeto protagonista $\mathrm{y}$, por supuesto, su voluntad de construir memoria. Tal como lo señalara Halbwachs (Jelin 20) no hay memoria individual que no esté enmarcada por la memoria colectiva. En El paso de los 
gansos, la memoria individual no podía resultar indemne frente a la violencia del marco histórico. Pero el diálogo entre ambos espacios no es para Alegría un asunto resuelto, los pequeños y grandes desafíos, lo ínfimo y lo trascendente, lo personal y lo social, son presentados en una yuxtaposición no jerarquizante que revierte las causalidades y los posicionamientos obvios. De tal modo, lo que en apariencias parece ser la superposición de la memoria individual por sobre la colectiva, al mismo tiempo resulta ser la inclusión de la memoria individual en el marco de la memoria colectiva.

Más aun, la novela parece ir más allá de sus propios límites, filtrándose desde una memoria narrativa a una memoria icónica. El libro se cierra con un segmento titulado "Fotos de Marcelo y Cristián (sic)", conformado por siete páginas sin numeración, que incluyen 12 fotografías ${ }^{5}$. Me parece importante remarcar, en este cierre del análisis, que el libro detenga la escritura narrativa lingüística y nos enfrente únicamente a las fotografías. Como si tras la detención de la palabra, del relato, de la épica, solo quedara la imagen. La indistinción autoral, ya que no se especifica quien es el autor de una u otra imagen, potencia la representación más que la identidad individual. Se trata de un conjunto de imágenes, en blanco y negro, que convoca diversos y centrales acontecimientos ocurridos en Santiago de Chile los días previos y posteriores al Golpe Militar. La secuencia, incluye la última marcha de apoyo al Presidente Allende, el entierro de Pablo Neruda, la Casa de Moneda bombardeada, detenidos en el Estadio Nacional, un allanamiento de agentes de la Dirección de Inteligencia Nacional (DINA) y un vehículo con militares armados recorriendo las calles de la ciudad.

De manera comprimida, las imágenes exponen una narrativa épica que transita hacia la derrota, inscrita en la violencia materializada en los rostros y cuerpos de las víctimas. Si, tal como señala Elizabeth Jelin, "El espacio de la

${ }^{5}$ Marcelo Montecino, hermano de Cristian, publica el año 2011, bajo el sello Ocho Libros, el volumen: Irredimible. Diario/1973. Este libro, en cuya portada aparecen como autores los nombres de ambos hermanos, contiene el relato de Marcelo en torno a su estadía en Chile el año 1973, y el periplo de Cristian que termina con su fusilamiento; además, el libro incluye diversas fotografías tomadas por ambos hermanos, varias de las cuales forman parte de El paso de los gansos. 
memoria es $[\ldots]$ un espacio de lucha política" (6), Alegría se inserta en esa lucha negándose a los usos institucionales de la memoria al inscribir al interior mismo del horror totalitario, una negatividad, una opacidad, irreductible, una escritura, ya sea mediante palabras o imágenes, de resistencia que rebasa los límites de su propia contingencia histórica.

\section{Bibliografía}

Alegría, Fernando. El paso de los gansos. New York: Ediciones Puelche, 1975. . "La literatura chilena en el contexto latinoamericano". Revista Araucaria de Chile $\mathrm{N}^{\circ} 19,1982$, pp. 113-119.

Bellido, Federico. "Operación Palace: El 23-F y las nuevas práctica de memoria". Revista internacional de historia de la comunicación $\mathrm{N}^{\circ} 6$, Vol. 1, Año 2016, pp. 103-123.

Chamorro, Jessenia. "El paso de los gansos (sic): Memoria ficcional del Golpe de Estado. En torno a la narrativa de Fernando Alegría". http://critica.cl/literatura-chilena/el-paso-de-los-gansos-memoria-ficcionaldel-golpe-de-estado . Revisado 16 de octubre, 2016.

Guerra, Lucía. "Historia y memoria en la narrativa de Fernando Alegría". Revista chilena de literatura $\mathrm{N}^{\circ} 48$, pp. 23-38.

Jelin, Elizabeth. Los trabajos de la memoria. Madrid: Siglo XXI, 2002.

Opaso, Cristián. "Cristian Montecinos: Asesinato por equivocación". http://www.derechos.org/nizkor/chile/libros/reporter/capII16.html. Revisado 16 de octubre, 2016.

Pabón, Carlos. "De la memoria: estética, estética y autoridad". Basile, Teresa (coord.). Literatura y violencia en la narrativa latinoamericana reciente. $\mathrm{La}$ Plata: Universidad Nacional de La Plata, 2015. 